\title{
Peningkatan Kemampuan Guru-guru Matematika SMP dalam Melaksanakan Assessment For Learning dan Assessment As Learning
}

\author{
Budiyono, Mardiyana
}

Universitas Sebelas Maret

email: budiyono@staff.uns.ac.id

\begin{abstract}
Abstrak
Untuk meningkatkan kemampuan guru Matematika SMP di Kota Surakarta dalam melaksanakan assessment for learning ( $\mathrm{AfL}$ ) dan assessment as learning (AaL), pelatihan implementasi AfL dan AaL bagi guru-guru Matematika di Surakarta telah dilaksanakan. Pelatihan dilaksanakan secara baik pada kurun waktu 21 Agustus 2019 sampai dengan 18

September 2019 secara in-on-in. Kepada para peserta pelatihan diundang untuk memperoleh pengetahuan mengenai AfL dan AaL di Aula SMP Negeri 26 Surakarta. Setelah itu kepada para peserta dimohon untuk dapat mengimplementasikan AfL dan Aal di kelasnya masing-masing, kemudian menuliskan dan mengirimkan laporannya kepada tim instruktur paling lambat 11 September 2019. Kemudian, para peserta pelatihan diundang kembali di Aula SMP Negeri 26 Surakarta untuk mendiskusikan pelaksanaan AfL dan AaL yang telah dilakukannya. Dengan mendengkarkan laporan yang disampaikan dan diskusi di antara peserta, dapat disimpulkan bahwa para peserta pelatihan memperoleh pengetahuan yang baik mengenai AfL dan AaL dan telah dapat mengimplementasikannya di kelas dengan baik.
\end{abstract}

Kata Kunci: AfL, AaL, matematika, guru SMP, Surakarya

\section{PENDAHULUAN}

Menurut Panduan Penilaian oleh Pendidik dan Satuan Pendidikan untuk Sekolah Menengah Pertama yang dikeluarkan oleh Direktorat Pembinaan Sekolah Menengah Pertama (DPSMP), Direktorat Jenderal Pendidikan dan Menengah, Kementerian Pendidikan dan Kebudayaan pada tahun 2017, terdapat tiga jenis assessment (penilaian, asesmen), yaitu assessment of learning (AoL), assessment for learning (AfL), dan assessment as learning (AaL) (DBSMP, 2016). Menurut buku tersebut, AoL merupakan penilaian yang dilaksanakan setelah pembelajaran selesai. Contoh AoL adalah ujian nasional, ujian sekolah, dan ujian sumatif lainnya. AfL dilakukan selama proses pembelajaran berlangsung dan tujuan utamanya memberikan umpan balik terhadap proses belajar peserta didik, memantau kemajuan, dan menentukan kemajuan belajarnya. AaL mirip dengan AfL, tetapi AaL melibatkan peserta didik secara aktif dalam kegiatan penilaian. Pada AaL, peserta didik diberi pengalaman untuk mengembangkan metakognisinya, yaitu kemampuan untuk menilai kemajuan belajarnya sendiri.

Dalam panduan tersebut dinyatakan bahwa seharusnya guru lebih banyak melakukan AaL dibandingkan dengan dua jenis penilaian yang lain. Hal tersebut ditunjukkan oleh gambar berikut. 


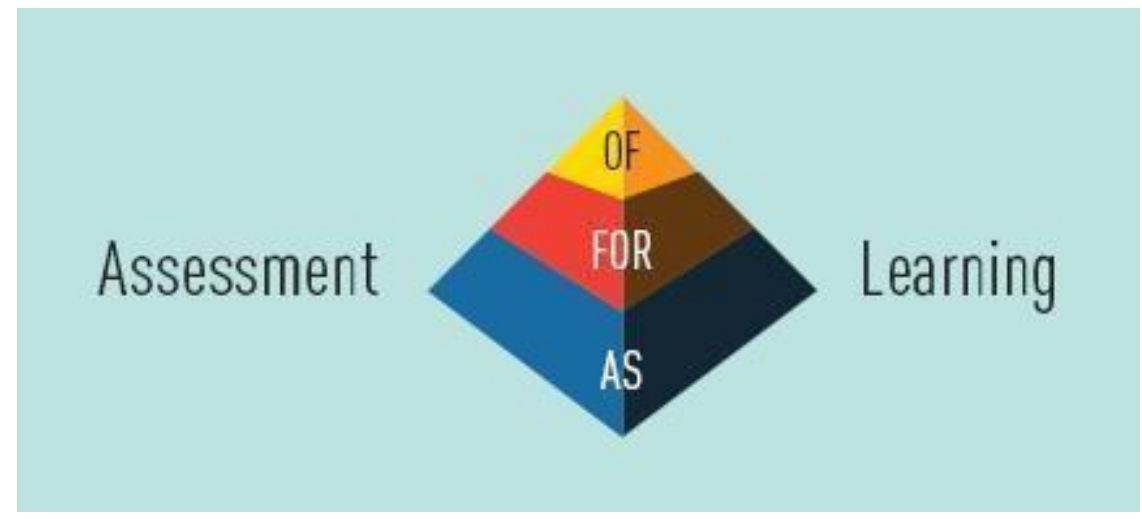

Gambar 1. Konfigurasi jenis penilaian yang seharusnya menurut Direktorat Pembinaan Sekolah Menengah Pertama (2017)

Namun kenyataannya, pada praktik penilaian di Indonesia, sebagian besar guru hanya melakukan AoL, sedikit yang telah melakukan AfL dalam bentuk penilaian formatif (walaupun tidak sepenuhnya benar), namun belum banyak guru yang melakukan AaL. Bahkan, buku panduan yang disebutkan di atas, walaupun di awalnya menyatakan bahwa guru seharusnya lebih banyak melakukan AaL, namun pada kenyataannya seluruh isi panduan tersebut hanya memberikan petunjuk mengenai pelaksanaan AoL, tidak memuat petunjuk pelaksanaan AfL dan AaL. Hal ini menunjukkan bahwa AfL dan AaL belum dikenal di Indonesia.

Di sisi lain, AfL dan AaL sudah banyak dilakukan di negara-negara lain. Misalnya, di Inggris, dengan dipelopori oleh Assessment Reform Group, para guru sudah melaksanakan AfL sejak lama. Beberapa peneliti, antara lain Young (2005) dan Stigins \& Chapuis (2006), menyatakan bahwa jika digunakan dengan baik, AfL dapat meningkatkan kesuksesan dan prestasi belajar siswa.

Senada dengan AfL, AaL juga sudah banyak dilakukan di negara-negara lain. Misalnya yang dilakukan oleh Almqvist, et. al. (2016) yang melaksanakan AaL untuk pembelajaran musik di negara-negara Skandinavia. Hal yang sama dilakukan oleh Gibbons \& Kankkonen (2011) untuk pembelajaran pendidikan jasmani di Kanada. Di bidang pembelajaran bahasa, Lee \& Malk (2012) melaksanakan AaL di Hongkong. Lam (2015) menggunakan AaL untuk pembelajaran menulis di Amerika Serikat. Semua pelaksanaan AaL yang dilaksanakan oleh para peneliti di atas, menghasilkan simpulan yang senada, yaitu bahwa AaL telah dapat meningkatkan metakognisi siswa dalam pembelajaran yang pada akhirnya dapat meningkatkan prestasi belajar siswa.

Walaupun di luar Indonesia telah banyak peneliti yang mengimple-mentasikan AfL dan AaL, namun belum banyak dilaporkan implementasi AfL dan AaL pada pembelajaran matematika di Indonesia, khususnya di Kota Surakarta. Hal itu mungkin karena belum banyak guru-guru matematika di Kota Surakarta yang memahami konsep AfL dan AaL. Oleh karena itu dipandang perlu untuk melakukan pelatihan kepada guru-guru Matematika SMP di Kota Surakarta mengenai konsep dan implementasi AfL dan AaL.

\section{Tinjauan Pustaka}


Seperti disebutkan di depan, ada tiga jenis penilaian (asesmen), yaitu assessment of learning (AoL), assessment for learning (AfL), dan assessment as learning (AaL). Earl \& Katz (2006: 15) mengatakan bahwa pada sistem penilaian tradisional, proporsi kegiatan ketiga jenis penilaian tersebut dapat digambarkan pada Gambar 2 berikut.

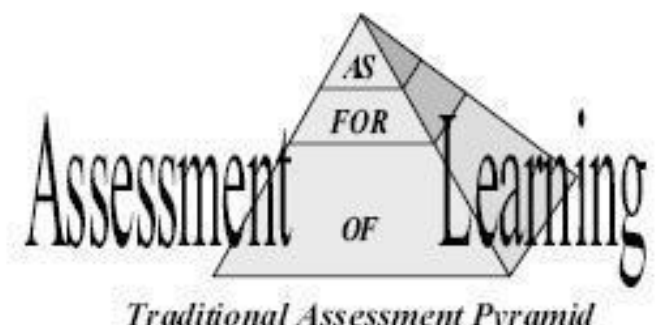

Gambar 2. Konfigurasi Sistem Penilaian Tradisional

Praktik penilaian yang dilaksanakan dewasa ini, terutama di Indonesia, digambarkan seperti piramid pada Gambar 2 tersebut. Sebagian besar (mungkin, hampir 90\%) penilaian yang dilakukan guru adalah AoL yang tujuan utamanya adalah untuk memberikan nilai kepada siswa. Jika penilaian yang dilakukan oleh guru sebagian besar adalah AoL, maka penilaian tidak memberikan sumbangan apa-apa kepada peningkatan proses pembelajaran siswa. AoL seharusnya tidak dilakukan oleh guru, tetapi dilakukan oleh pihak eksternal (di luar guru).

Earl \& Katz (2006) mengatakan bahwa untuk meningkatkan kualitas pembelajaran, maka seharusnya bobot implementasi yang paling besar adalah pada AaL, disusul oleh AfL, baru kemudian AoL, seperti digambarkan pada Gambar 3.

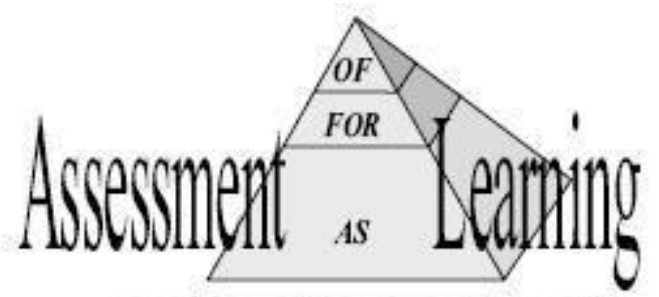

Reconfigured Assessment Pyramid

Gambar 3. Konfigurasi Sistem Penilaian Baru

\section{Assessment for Learning}

Assessment Reform Group di Inggris yang disponsori oleh British Educational Research Association telah melakukan riset mendalam mengenai pelaksanaan AfL di Inggris sejak beberapa lama. Mereka mengklaim bahwa AfL dapat meningkatkan kemampuan siswa dalam berbagai mata pelajaran, seperti yang dikemukan oleh Young (2005) dan Stiggins \& Chappuis (2006).

Assessment for learning ( $\mathrm{AfL}$ ) didefinisikan sebagai using evidence and feedback to identify where students are in their learning, what they need to do next, and how 
best to achieve this (www.geography.org.uk). Dengan kata lain, AfL adalah the process of seeking and interpreting evidence for use by learners and their teachers to decide where the learners are in their learning, where they need to go, and how best to get there. Berdasarkan hal-hal tersebut dapat dikatakan bahwa AfL adalah proses untuk mencari dan menginterpretasikan bukti-bukti yang ada untuk digunakan bagi siswa dan guru untuk menentukan pada posisi mana siswa-siswa telah belajar, apa yang harus dikerjakan kemudian, dan bagaimana cara terbaik untuk mencapai tujuan yang diinginkan.

AfL dikembangkan berdasar kepada pemikiran bahwa kemampuan siswa dapat meningkat secara optimal, jika mereka mengerti tujuan pembelajaran, mengetahui posisi mereka dalam kaitannya dengan tujuan pembelajaran, dan mengerti cara mencapai tujuan pembelajaran tersebut.

Ada 10 prinsip dalam AfL, yaitu:

(1) AfL should be part of effective planning of teaching and learning,

(2) AfL should focus on how students learn,

(3) AfL should be recognized as central to classroom practice,

(4) AfL should be regarded as a key professional skill for teachers,

(5) AfL should be sensitive and constructive because any assessment has an emotional impact,

(6) AfL should take account of the importance of learner motivation,

(7) AfL should promote commitment to learning goals and a shared understanding of the criteria by which they are assessed,

(8) Learner should receive constructive guidance about how to improve,

(9) AfL should develops learners' capacity for self-assessment so that they can become reflective and self managing, dan

(10) AfL should recognise the full range of achievement of all learners.

Ada empat karakteristik kunci yang harus dipahami oleh guru dalam melaksanakan

AfL, yaitu: (1) using effective questioning techniques, (2) using feedback strategies, (3) sharing learning goals, dan (4) peer and self-assesment.

Untuk mewujudkan AfL yang efektif, hal-hal berikut harus dilakukan oleh guru:

(1) emphases the interactions between learning and manageable assessment strategies that promote learning,

(2) clearly expresses for the student and teacher the goals of the learning activity,

(3) reflects a view of learning in which assessment helps students learn better, rather than just achieve a better mark,

(4) provides ways for students to use feedback from assessment,

(5) helps students take responsibility for their own learning,

(6) is inclusive of all learners.

Di sisi lain, Clarke (2005: 1-2) mengatakan bahwa pelaksanaan AfL (yang oleh Clarke disebut penilaian formatif) harus mengikuti strategi berikut:

(1) clarifying learning objectives and success criteria at the planning stage, as framework for formative assessment processes,

(2) sharing learning objectives and success criteria with students, both long term and for individual lessons, 
(3) appropriate and effective questioning which develops the learning rather than attempts to measure it,

(4) focusing oral and written feedback, whether from teacher or student, around the development of learning objectives and meeting of targets,

(5) organising targets so that students' achievement is based on previous achievement as well as aiming for the next step,

(6) involving students in self- and peer evaluation, dan

(7) raising students' self-efficacy and holding a belief that all students have potential to learn and achieve.

Seperti diuraikan, inti dari AfL adalah pemberian balikan kepada siswa secepat mungkin terhadap kesalahan-kesalahan yang dilakukan oleh siswa. Wujud pemberian balikan kepada siswa tersebut dapat bermacam-macam.

\section{Assessment as Learning}

AaL pada prinsipnya memfokuskan kepada pembelajaran siswa dan menggunakan penilaian sebagai proses untuk membangkitkan metakognisi siswa (Earl \& Katz, 2006; Dann, 2014; Sadeghi \& Rahmati, 2017, Lam, 2005).

AaL muncul dari suatu pemikiran bahwa belajar bukan sekedar menstransformasi pengetahuan seseorang kepada orang lain, melainkan suatu proses konstruksi kognitif yang terjadi ketika seseorang berhadapan dengan ide-ide atau konsep-konsep yang baru. Dalam konteks ini, "students are critical connectors between assessment and learning” (Earl \& Katz, 2006: 41). Ketika siswa membentuk pengetahuan menurut konstruksinya sendiri, siswa harus menjadi penilai kritis yang make sense of information terkait dengan pengetahuan yang telah dimilikinya, yang hal ini digunakan untuk membuat atau mengerti konsep yang baru. Ini adalah "regulatory procees in metacognition" (Earl \& Katz, 2006: 41) di mana siswa dapat melakukan monitoring terhadap dirinya sendiri, kemudian menggunakan apa yang dia temukan dari monitoring tersebut untuk melakukan penyesuaian, adaptasi, dan perubahanperubahan baru dalam proses berpikirnya.

Ide AaL muncul dari riset mengenai bagaimana belajar terjadi dan dicirikan oleh refleksi diri mengenai dirinya bahwa dirinya telah belajar dan membuat sejumlah penyesuaian sedemikian hingga mereka memperoleh pengertian yang lebih mendalam (Earl \& Katz, 2006; Ciobanu, 2014; Elbra-Ramsay \& Backhouse, 2015; Gupta, 2016). AaL memperluas tugas guru untuk melakukan perencanaan mengenai pembelajaran dan penilaian yang memungkinkan seluruh siswa berpikir mengenai dan memonitor proses belajarnya sendiri. Dalam beberapa penelitian, misalnya penelitian Laister (2016), pemberian kemampuan metakognisi siswa dapat meningkatkan prestasi belajar siswa, termasuk prestasi belajar matematika.

AaL dikembangkan berdasarkan keyakinan bahwa siswa dapat beradaptasi, dapat fleksibel, dan independen dalam proses pembelajaran dan penentuan keputusannya sendiri. Dengan demikian, AaL membantu siswa untuk menjadi siswa yang dapat belajar secara mandiri (independent learners). Untuk dapat menjadi independent learners, siswa harus dapat mengembangkan kombinasi skills, sikap, dan disposisi yang memadai mengenai self-monitoring dan self-evaluation. Untuk dapat 
menjadi independent learners, peran guru sangatlah penting dalam merencanakan dan melaksanakan proses pembelajaran.

Menurut Earl \& Katz (2006: 43), peran guru dalam membangun independent learners melalui AaL adalah sebagai berikut:

1. model and teach the skill of self-assessment;

2. guide students in setting goals, and monitoring their progress toward them;

3. provide exemplars and models of good practice and quality work that reflect curriculum outcomes;

4. work with students to develop clear criteria of good practice;

5. guide students in developing internal feedback or self-monitoring mechanism to validate and question their own thingking, and to become comfortable with the ambiguity and uncertanty that is inevitable in learning anything new;

6. provide regular and chalenging opportunities to practice, so that students can become confident, competent self-assesors;

7. monitor students' metacognitive processes as well as their learning, and provide descriptive feedback;

8. create an environment where it is safe for students to take chances and where support is readily available.

Apa yang dikatakan oleh Earl \& Katz di atas adalah rambu-rambu pelaksanaan AaL secara umum, yaitu bagaimana merancang dan melakukan pembelajaran dengan mengacu kepada prinsip-prinsip di atas. Pertanyaannya kemudian adalah jenis penilaian seperti apa yang dapat dipakai untuk mengimplementasikan AaL. Beberapa literatur menuliskan dapat menggunakan penilaian diri sendiri (self-assessment) dan penilaian teman sejawat (peer-assessment), seperti yang disebutkan oleh DBSMP (2016). Ada yang menggunakan portofolio. Penelitian ini akan mengkaji lebih lanjut manakah yang cocok untuk mengembangkan AaL untuk pembelajaran matematika di SMP.

\section{Metakognisi}

Di depan telah disebutkan bahwa pelaksanaan AaL bertujuan untuk meningkatkan kemampuan metakognisi siswa. Dengan demikian, metakognisi menjadi fokus dari pelaksanaan AaL. Seperti yang dikatakan oleh Schneider \& Artelt (2010), kemampuan metakognisi siswa dapat dilatihkan oleh guru, kepada usia anak-anak sekalipun. Dia katakan bahwa "the basic assumption was that although children in most cases do not efficiently monitor the effectiveness of strategies they use, they can be trained to do so".

Lebih lanjut, Scheider \& Artelt (2010) mendefinisikan metakognisi sebagai berikut.

Metacognition refers to people's knowledge of their own information-processing skills, as well as knowledge about the nature of cognitive tasks, and of strategies for coping with such tasks. Moreover, it also includes executive skills related to monitorin and self-regulation of one's own cognitive acivities.

Sejak Flavel mengenalkan konsep mengenai metakognisi pada tahun 1976, sebagian besar pakar membedakan metakognisi menjadi dua komponen, yaitu 
komponen pengetahuan (kwnoledge) dan kompoen keterampilan (skills) (Desoete, 2008). Menurut Flawel (Desoete, 2008), pengetahuan metakognisi dapat dijelaskan atas the knowledge, awareness, dan deeper understanding kepada proses dan produk kognitif. Di sisi lain, menurut Brown (Desoete, 2008), keterampilan metakognisi dapat dilihat dari control people have over their own proses kognitif. Menurut Schneider dan Artlet (2010), keterampilan metakognisi sering disebut procedural metacognitive knowledge.

Di sisi lain, Earl \& Katz (2016: 41) mengatakan ada dua dimensi metakognisi, yaitu knowledge of cognition dan regulation of cognition. Knowledge of cognition terdiri atas: (1) pengetahuan mengenai dirinya sendiri sebagai pebelajar (learners) dan faktorfaktor yang mempengaruhinya, (2) pengetahuan mengenai strategi belajar, dan (3) pengetahuan mengenai kapan dan mengapa menggunakan strategi tertentu. Regulation of cognition terdiri atas: (1) perencanaan: menentukan tujuan belajar dan mengaktifkan kembali pengetahuan-pengetahuan yang mendasarinya, (2) regulasi: melakukan monitoring dan evaluasi diri, dan (3) evaluasi: melakukan penilaian (appraising) proses dan produk hasil belajar.

Di luar definisi-definisi yang telah disebutkan, tentu masih banyak definisi metakognisi yang lain. Peneliti masih akan mengelaborasi definisi-definisi di luar definisidefinisi metakognisi yang telah ditulis dan pada akhirnya akan menentukan definisi konseptual dan definisi operasional yang tepat terkait dengan materi pembelajaran yang dilibatkan (yaitu matematika) dan subjek didik yang terlibat (yaitu siswa-siswa SMP).

\section{Tujuan Kegiatan}

Kegiatan pengabdian kepada masyarakat ini bertujuan untuk memberikan bekal kepada guru-guru Matematika SMP di Kota Surakarta mengenai konsep AfL dan AaL yang kemudian para guru mengimplementasikan AfL dan AaL tersebut pada pembelajaran matematika di kelas.

\section{METODE KEGIATAN}

Upaya peningkatan kemampuan melaksanakan AfL dan AaL bagi guru-guru Matematika SMP di Kota Surakarta dilaksanakan melalui kegiatan pelatihan, melalui langkah-langkah pokok berikut.

Pertama, dilakukan pelatihan implementasi AfL dan AaL kepada guru-guru Matematika SMP di Kota Surakarta sebanyak 52 orang pada Rabu 21 Agustus 2019 mulai pukul 08.00 sd pkl 15.00 di SMP Negeri 26 Surakarta. Pelaksanaan pelatihan dikoordinasikan dengan Pengurus MGMP Matematika Kota Surakarta. Setelah memperoleh pelatihan, kepada para guru diminta untuk mengimplementasikan konsep AfL dan AaL saat pembelajaran di kelas. Untuk selanjutnya, kepada para guru diundang lagi untuk berkumpul guna melaporkan dan berdiskusi mengenai implementasi AfL dan AaL yang telah guru-guru lakukan pada Rabu 18 September 2019. 


\section{HASIL KEGIATAN}

\section{Pelaksanaan Assessment for Learning (AfL)}

Nama AfL tampaknya belum dikenal oleh para guru, tetapi mereka telah melakukannya. Pada umumnya guru mengenal AfL sebagai penilaian formatif. Namun demikian, para guru banyak yang masih salah memahami hakekat penilaian formatif. Banyak guru yang mengatakan bahwa ketika guru memberikan penilaian harian, maka guru tersebut telah memberikan penilaian formatif. Hal seperti ini tidaklah benar, sebab tanpa diberikannya balikan (feedback) kepada siswa tentang kesalahannya, penilaian harian tersebut bukanlah penilaian formatif.

Dari serangkaian diskusi ketika pelatihan, dapat disimpulkan bahwa pada umumnya para guru telah melaksanakan AfL di kelas pada pembelajaran sehari-hari, yaitu telah memberikan balikan kepada siswa yang melakukan kesalahan. Namun demikian, sebagian besar guru memberikan balikannya secara klasikal, tidak secara individual. Ada kalanya pemberian balikan dilaksanakan secara kelompok, misalnya jika pada pelaksanaan pembelajarannya dibentuk kelompok. Namun demikian, semua peserta sepakat bahwa pemberian balikan seyogyanya dilakukan secara individual.

Pelaksanaan AfL di kelas dapat juga dilakukan melalui pemberian pertanyaan kepada siswa, lalu kemudian guru memberikan bimbingan dan arahan manakala siswa salah menjawabnya. Dalam konteks ini, guru disarankan untuk menyebut nama siswa ketika memberikan pertanyaan kepada siswa, supaya siswa merasa bahwa dia dikenal dan diperhatikan oleh gurunya.

Persoalan utama yang dikeluhkan guru adalah banyaknya materi dalam kurikulum yang harus disampaikan kepada siswa. Karena alasan ini lah, banyak guru yang tidak dapat melaksanakan AfL di kelas dengan optimal. Namun demikian, persoalan ini dapat diselesaikan dengan memeriksa pekerjaan siswa di rumah, kemudian memberikan balikan kepada semua kertas jawaban siswa yang masih salah. Dengan demikian, maka pelaksanaan AfL menjadi lebih efisien. Namun demikian, hal seperti ini pun masih mempunyai kendala, yaitu harus disediakannya cukup waktu bagi guru untuk memeriksa pekerjaan siswa di rumah.

Persoalan yang muncul pada pelaksanaan AfL adalah bahwa setiap siswa memiliki kemampuan yang berbeda (heterogen), sehingga penerapan yang diberikan dalam AfL pada setiap siswa pun berbeda-beda. Dalam konteks ini, guru dituntut untuk terampil dalam memberikan balikan sesuai dengan yang dibutuhkan oleh siswa.

Membaca dan mendengarkan laporan dari peserta pelatihan serta diskusi pada 18 September 2019 dapat disimpulkan bahwa seluruh peserta pelatihan telah dapat melaksanakan AfL dengan baik seperti yang dituliskan pada pedoman pelatihan.

\section{Pelaksanaan Assessment as Learning (AaL)}

Sama halnya dengan AfL, para guru belum mengenal nama AaL. Namun demikian, berbeda dengan AfL, sepertinya baru sangat sedikit guru yang telah melaksanakan AaL. Mereka melaksanakan AaL dalam bentuk penilaian diri dan penilaian teman 
sejawat, namun demikian, belum tampak bagaimana usaha guru untuk meningkatkan metakognisi siswa secara terencana.

Terkait dengan pelaksanaan penilaian, banyak para guru yang mengeluh bahwa siswanya banyak yang tidak serius mengerjakan tugas-tugas. Mereka hanya menyalin saja dari pekerjaan siswa lainnya. Keseriusan melaksanakan tugas-tugas penilaian (baik secara individual maupun kelompok) sepertinya memang merupakan hal yang harus ditingkatkan kualitasnya.

Pada penilaian AaL agar siswa dapat mengetahui kelebihan dan kekurangan diri sendiri, maka pada langkah-langkah penilaian (menurut ibu guru diberikan kunci jawaban, agar nantinya antara siswa dapat terjadi diskusi mengenai hasil pengerjaannya). Dengan kata lain, pada langkah penilaian diberikan kuncinya saja atau hasil jawaban, jadi bukan langkah-langkah pengerjaan, karena kalau diberikan langkah-langkah pengerjaan tidak terjadi proses berpikir siswanya.

Terkait dengan soal yang diberikan oleh guru pada AaL, akan lebih bagus jika soalsoal yang diberikan adalah soal yang cara penyelesaiannya dapat menggunakan berbagai macam cara, sehingga nantinya siswa dapat membandingkan pengerjaannya dengan siswa lain, lalu memikirkan cara yang terbaik seharusnya seperti apa.

Berdasarkan diskusi pada pelatihan yang dilaksanakan pada 21 Agustus 2019 dapat disimpulkan bahwa sebagain besar guru belum pernah melaksanakan AaL secara terencana. Alasan yang disampaikan adalah: (1) para guru belum pernah mengenal nama AaL, (2) pada pelatihan-pelatihan mengenai penilaian, yang banyak dibicarakan adalah pelaksanaan AoL dan sedikit AfL (dengan nama penilaian formatif), (3) belum pernah ada pelatihan penilaian yang membicarakan AaL. Oleh karena itu, semua peserta sangat berminat untuk mendengarkan uraian mengenai AaL.

Berdasarkan laporan para peserta pelatihan ketika melaksanakan AaL di kelas dan diskusi yang dilakukan pada 18 September 2019 dapat disampaikan temuan bahwa sebagian besar peserta belum dapat melaksanakan AaL dengan tepat. Jika dilihat persentasenya, hanya sekitar $50 \%$ peserta yang telah melaksanakan AaL dengan tepat. Ini mungkin dikarenakan agak sulit merencanakan kegiatan yang dapat mendorong timbulnya metakognisi siswa.

\section{SIMPULAN DAN SARAN}

Berdasarkan serangkaian kegiatan pelatihan dan implementasi di lapangan oleh para guru, maka disimpulkan hal-hal berikut.

1. Kegiatan pelatihan implementasi assessment for learning (AfL) dan assessment as learning (AaL) bagi guru-guru Matematika SMP di Kota Surakarta telah berjalan dengan baik. Pada pelatihan disepakati pengertian utama AfL dan AaL sebagai berikut. AfL adalah penilaian yang dilakukan selama proses pembelajaran berlangsung dengan tujuan utamanya memantau belajar siswa, memberikan umpan balik kepada siswa untuk kemajuan belajarnya, dan memperbaiki proses pembelajaran di kelas. AaL mirip dengan AfL, tetapi AaL melibatkan peserta didik secara aktif dalam kegiatan penilaian sedemikian hingga siswa dapat mengembangkan metakognisinya sendiri. 
2. Pada umumnya guru mengenal AfL sebagai penilaian formatif dan sudah sejak lama mengimplementasikan penilaian formatif tersebut. Namun demikian, kebanyakan guru masih belum mengerti benar makna dan tujuan penilaian formatif itu sendiri. Kebanyakan guru menganggap bahwa jika seorang guru telah memberikan penilaian harian, maka guru tersebut telah melakukan penilaian formatif. Anggapan ini salah. Penilaian harian dapat berfungsi sebagai penilaian formatif jika hasil pekerjaan siswa diperiksa dan bagi mereka yang melakukan kesalahan diberikan balikan bagaimana memperbaiki kesalahan tersebut. Kecuali hal tersebut, wujud AfL tidak terbatas kepada penilaian harian, tetapi juga kegiatan lain, seperti pemberian pertanyaan di tengah-tengah pembelajaran, yang kemudian diberikan balikan ketika siswa salah menjawab pertanyaan.

3. Seharusnya AfL dilaksanakan di tengah-tengah atau selama pembelajaran untuk memperbaiki kesalahan-kesalahan yang dilakukan oleh siswa, tidak seperti penilaian harian yang diberikan di akhir suatu waktu.

4. Berbeda dengan AfL, sebagian besar guru belum mengenal dan melaksanakan AaL secara terstruktur dengan baik.

5. Pelatihan yang diteruskan dengan implementasi di lapangan telah berhasil meningkatkan pengetahuan dan keterampilan guru dalam melaksanakan AfL dan AaL di kelas, walaupun untuk implementasi AaL masih diperlukan usaha yang lebih keras lagi.

Berdasarkan simpulan di atas, disarankan hal-hal berikut.

1. Kepada para guru disarankan untuk terus meningkatkan keterampilannya dalam melaksanakan AfL dan Aal, sehingga harapan pemerintah yang dituangkan dalam Buku Panduan Penilaian oleh Pendidik dan Satuan Pendidikan untuk Sekolah Menengah Pertama, yang diterbitkan oleh Direktorat Pembinaan Sekolah Menengah Pertama tahun 2017, agar para guru lebih banyak melakukan AaL dan AfL dibandingkan dengan AoL dapat diwujudkan.

2. Kepada para kepala sekolah disarankan untuk memantau pelaksanaan AfL dan AaL di sekolah agar prestasi siswa-siswa dapat meningkat dengan cepat, mengingat menurut berbagai hasil penelitian, AfL dan AaL jika dilaksanakan dengan baik akan meningkatkan prestasi belajar siswa.

3. Walaupun pada Buku Panduan Penilaian oleh Pendidik dan Satuan Pendidikan untuk Sekolah Menengah Pertama, yang diterbitkan oleh Direktorat Pembinaan Sekolah Menengah Pertama tahun 2017 disarankan agar para guru lebih banyak melakukan AaL dan AfL dibandingkan dengan AoL, namun demikian pada buku panduan tersebut tidak dicontohkan secara eksplisit cara-cara melaksanakan AfL dan AaL. Buku panduan tersebut sebagian besar berisi panduan untuk melaksanakan AoL. Oleh karena itu, disarankan kepada Direktorat Pembinaan Sekolah Menengah Pertama untuk melengkapi panduan tersebut dengan cara-cara praktis melakukan AfL dan AaL. 


\section{DAFTAR PUSTAKA}

Almqvist, C. F., Vinge, J., Vakeva, L., \& Zanden, O. (2017). Assessment as learning in music education: The risk of "criteria compliance" replacing "learning" in the Scandinavian countries. Research Studies in Music Education. 39(1): 3 - 18.

Ciobanu, M. (2014). In the midle: Whose learning is it way? Increasing students"s engage-ment through assessment as learning techniques. OAME/AOEM Gazzete. 16-21.

Clarke, S. 2005. Formative assessment in the secondary classroom. London: Hodder Murray.

Dann, R. (2017). Assessment as learning: blurring the boundaries of assessment and learning for theory, policy, and practice. Assessment in Education: Principles, Policy \& Practice. 21(2): $149-166$.

Direktorat Pembinaan Sekolah Menengah Pertama (DBSMP). (2017). Panduan Penilaian oleh Pendidik dan Satuan Pendidikan untuk Sekolah Menengah Pertama. Jakarta: Direktorat Pembinaan Sekolah Menengah Pertama.

Earl, L. \& Katz, S. (2006). Rethinking classroom assessment with purpose in mind. Manitoba: Western and Northern Canadian Protocol for Collaboration in Education.

Elbra-Ramsay, C. \& Backhouse, A. (2015). „So, you want us to do the marking?!" peer review and feedback to promote assessment as learning. Journal of Pedagogic Development. 5(1): 19 - 30.

Gibbons, S.L. \& Kankkonen, B. (2011). Assessment as learning in physical education: Making assessment meaningful for secondary school students. Physical \& Health Education. 76(4): 6-12.

Gupta, K. 2016. Assessment as Learning: Students learn, self-correct, and collaborate. The Science Teacher. $43-46$.

Lee, I. \& Mak, P. (2012). Assessment as learning in the classroom. Assessment and Learning. 3: $66-78$.

Sadeghi, K. \& Rahmati, T. (2017). Integrating assessment as, for, and of learning in a large-scale exam. Assessing Writing. 34. 50-61.

Schneider, W. \& Artelt, C. 2010. Metacognition and mathematics education. ZDM Mathematics Education. 42. 149-161

Stiggins, R. \& Chapuis, J. (2006). What a difference a word makes: Assessment for learning rather than assessment of learning helps students succeed. Tersedia di http://www.nsdc.org/library/publications/jsd.

Young, E. (2005). Assessment for Learning: Embedded and extending. Tersedia pada http://www.Itscotland.org.uk/assess/for/index.asp. 